\title{
Renowned researchers inducted into hall of
}

\section{fame}

n Cite as: CMAJ 2017 May 23;189:E735-6. doi: 10.1503/cmaj.1095422

$\mathrm{T}$ his year's Canadian Medical Hall of Fame inductees revolutionized health care through research, law and community involvement. Founded in 1994, the hall of fame has recognized 132 Canadians' contributions to medicine. Six laureates were inducted on May 4 in Quebec City.

"It's a great group, an impressive group to be sure, and particularly heartwarming to be able to honour two of them so close to home [Quebec City]," says Lissa Foster, executive director of the hall of fame. The list this year also shows that "Canadians are on the scene, making an extraordinary contribution," she adds.

Some of the achievements of this year's hall of fame inductees are highlighted here.

Dr. Michel G. Bergeron founded Laval University's Infectious Diseases Research Centre in 1974. Today, the Quebec Citybased research facility includes more than 150 scientists and researchers working to prevent and treat infections. Bergeron's microbicidal gel, also known as the invisible condom, continues to prevent the transmission of HIV and other sexually acquired infections. Bergeron has 25 patents, and has authored or co-authored over 400 articles. Among his many innovations, is a "lab-on-chip" to rapidly detect infections at point-of-care and lower deaths from infectious diseases. His honours include the Queen Elizabeth II Diamond Jubilee medal, Order of Canada and L'Ordre national du Québec.

Dr. Michel Chrétien now has over 600 publications in print. Back in the 1980s, he was the seventh most cited scientist in the world. Chrétien - founder of the Ottawa Institute of Systems Biology at the University of Ottawa and Director of Montreal University's laboratory in func- tional endoproteolysis - helped discover proprotein convertases through his 1967 pro-hormone theory. The convertases, groups of proteins that activate other proteins, act in the development of diseases such as cancer and diabetes.
Chrétien is a Fellow of the Canadian Academy of Health Sciences and an Officer of the Order of Canada. He received the McLaughlin Medal from the Royal Society of Canada. His brother is former Prime Minister Jean Chrétien.

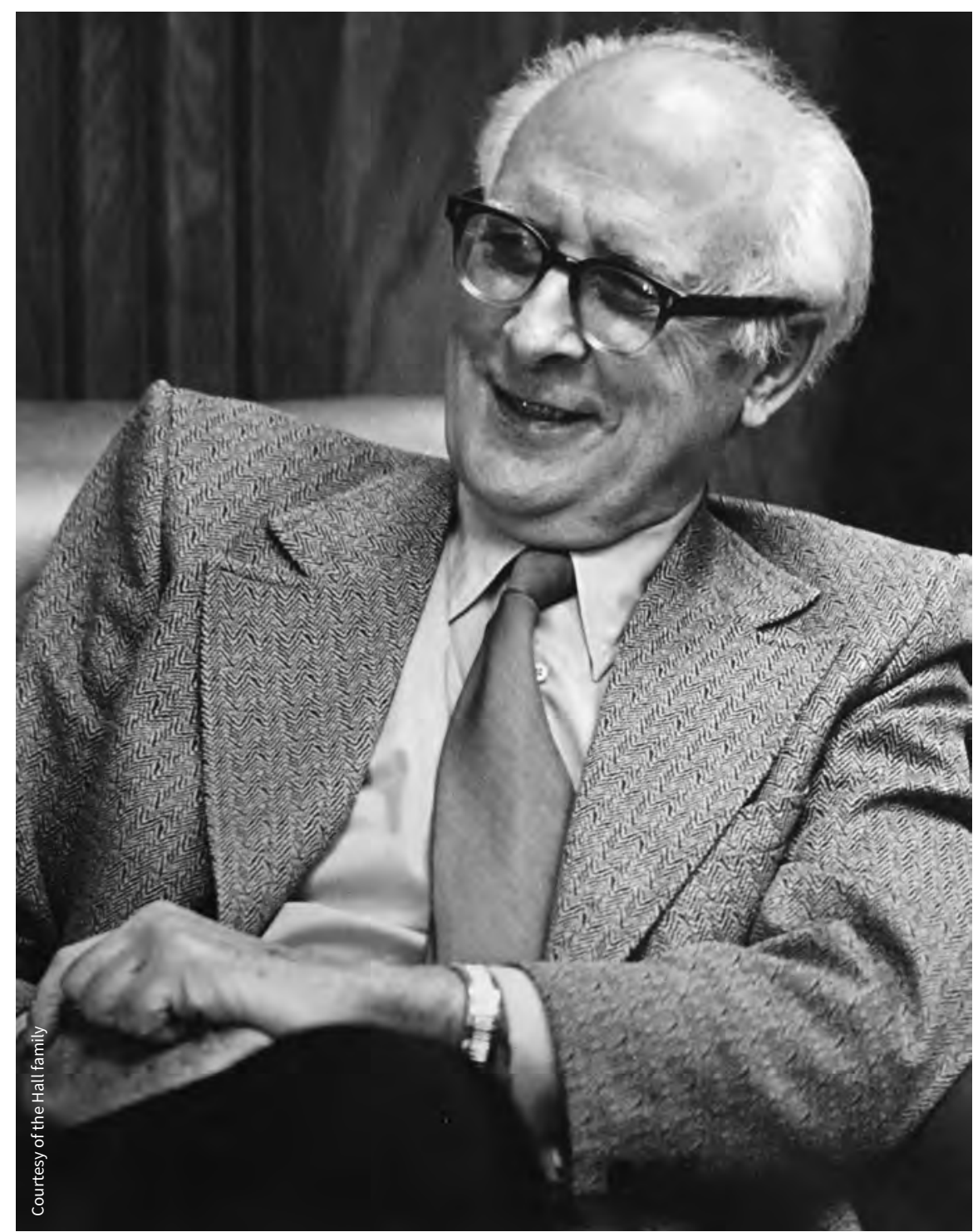

The late Justice Emmett Hall, known as one of the fathers of Medicare, was inducted into the Canadian Medical Hall of Fame on May 4. 
Dr. Richard Goldbloom, a long-time proponent for getting families involved in their child's health and care before leaving hospital, brought one of the first care-byparent units to Canada. The Goldbloom Medal in Pediatrics was created as a fitting testimony to his work as the former head of the pediatrics department and continuous advocate on behalf of children and their parents navigating Canada's medical system. In 2003, he was recognized with a Canada Post National Literacy Award. He is also an Officer of the Order of Canada.

The late Justice Emmett Hall is known as one of two fathers of Medicare, alongside Tommy Douglas. In 1961, he was invited by then-prime minister John Diefenbaker to lead the Royal Commission on Health Services. He recommended a universal, single-payer system, a model similar to what existed in his home province Saskatchewan. His law career culminated in his appointment to the Supreme Court in 1962. Even after retirement, Hall continued to influence the country's health policy. The 1984 Canada Health Act was inspired in large part by Hall's concerns over extra billing and user fees. Following his death at the age of 95 in 1995, The Justice Emmett Hall Memorial Foundation was created to celebrate and promote Canadian health policy.

Considered one of the world's top experts on Huntington disease, Dr. Michael R. Hayden is the most-cited author on the topic with over 800 publications. His focus on understanding the genetic pathways of Huntington disease has allowed doctors to shift focus from the disease's symptoms to its causes. This analysis of genetic roots also led him to research in other illnesses such as diabetes and coronary artery disease. The University of British Columbia's Hayden Lab has multiple research projects on Huntington disease in progress; their aim is to find a cure for the disease. Hayden's many awards include being named one of the 50 Canadians who have changed the world, in Ken McGoogan's book of the same name.
Dr. F Estelle R Simons has dedicated her career and research to the pharmacological management of allergies and asthma. In 1975, she founded the section of allergy and clinical immunology at the University of Manitoba in Winnipeg. She has taken on leadership roles in the national and international allergy communities, including being president of the Canadian Society of Allergy and Clinical Immunology. She brought the World Allergy Congress to Vancouver in 2003. She was the first to publish findings on reactions to mosquito saliva as part of her greater examination of environmental factors of allergies. Her current research is focused on developing a rapidly dissolving oral tablet to treat anaphylactic episodes in community settings. Simons is the author of nearly 600 publications, and has garnered numerous awards including the Canadian Medical Association Medal of Service.

Caroline O'Neill, CMAJ 